\title{
LEARNING ELECTRONICS THROUGH STORYTELLING
}

\author{
Libby Osgood and Nadja Bressan \\ Faculty of Sustainable Design Engineering \\ University of Prince Edward Island \\ eogood@upei.ca,nbressan@upei.ca
}

\begin{abstract}
STEM (Science, Technology, Engineering, and Math) initiatives have expanded to include 'art' with the moniker: STEAM (Science, Technology, Engineering, Art, and Math). This acknowledges the importance of creativity in the technical fields and poses the question: How do we incorporate art into the engineering classroom?

This paper presents one attempt to incorporate the art of storytelling in a first-year engineering design course in January 2021. It was found that compared with students who received a traditional lecture to learn basic electronic concepts, the students who used an illustrated storybook to learn the same concepts took significantly less time to replicate a sample circuit $(p<.001)$, and performed better in a post-activity assessment $(p>.05)$. These results indicate that the use of storytelling can be an effective way to transmit technical content in an engineering classroom, and further studies should be pursued.
\end{abstract}

Keywords: Storytelling, STEAM, Art, Electronics, Breadboard, Circuits, Education pedagogy, Engineering education

\section{INTRODUCTION}

Storytelling has been an effective medium to transmit data both visually and orally for thousands of years. From paintings on cave walls to schematics in engineering textbooks, information is conveyed through the use of imagery. Stories ensure vital knowledge is passed from one generation to the next, whether through origin stories or lectures on diodes and resistors. In addition to learning information through artistic modalities, engineering students express themselves artistically through their sketches, engineering drawings, $\mathrm{CAD}$, writing samples, designs, and presentations.

This acknowledgment of the vital role of artistic expression in traditionally technical fields is exhibited in the change from STEM (science, technology, engineering, and math) to STEAM (science, technology, engineering, art, and math) initiatives in the K-12 setting [1-3]. Design projects and project-based learning are ideal for fostering creativity and artistic expression in the engineering curriculum [4]. The challenge for engineering educators is how to incorporate art within the traditional classroom as well, not just in the deliverables that students submit but also in the delivery of the material itself.

For a simple way to infuse art in delivery methods, educators can ensure their slides are visually appealing and speak in an engaging tone. A more creative incorporation of art could lead educators away from the conventional lecture to convert their slides into a narrative to transmit data through allegory. By creating characters and anthropomorphizing technical data, the complex topic could be better understood. Storytelling can convey information to the students to make complex ideas more accessible and engaging [5-7].

This paper outlines one attempt to incorporate art in the classroom and make learning traditionally didactic information more interesting through the use of storytelling. Students in two sections of a first-year engineering design course were introduced to basic electronics concepts using different delivery methods to determine whether storytelling can be as effective as traditional methods for learning technical information.

\section{BACKGROUND RESEARCH}

Storytelling has been documented as a content delivery method in multiple fields. Nursing students improve their listening skills to better understand their patients' needs through the use of storytelling [8,9]. In computer science and information management fields, storytelling is used as an instructional aid to encourage critical thinking [5].

According to Papadimitriou, storytelling is used in three principal ways to convey technical information:

(i) A story can provide historical context to give definition and shape to a concept.

(ii) A story can be used to explain an idea to help students understand the concept more fully.

(iii) Lessons can be embedded within a story [10].

In the engineering context, storytelling is used in different forms. Gamification provides a way to convert an 
entire course into a game, creating incentives for students to excel and providing immediate feedback on their progress $[11,12]$. To learn a particular concept, case studies and scenarios engage students' imagination as they work through the problem $[6,13]$. To explore ethical concepts, video games and 'choose your own adventure' activities provide multiple interaction points after the initial scenario is proposed, which emphasize the complexity and consequences of a particular decision $[14,15]$.

Interactive electronics labs and learning simulations are creative ways to allow students to explore basic circuitry, especially in courses where students cannot be present in person $[16,17]$. Escape rooms and scavenger hunts require students to physically exert themselves to learn a particular concept [18]. Science fiction provides numerous examples of engineering mechanics and allows students to see the role of engineers in society [19].

Though this paper is focused on delivery methods to students, it should be noted that storytelling is also found in the deliverables that engineering students are asked to submit. Digital storytelling is one form of creatively expressing technical content, such as creating a movie instead of writing a lab report [20,21]. Additionally, the use of software prototypes, dioramas, and automatons can express design concepts and simultaneously tell a story [22-25].

In the broader educational context, Fang suggests replacing science textbooks with educational novels that present information in a storybook format for middleschool students to increase the science language skills and improve engagement [26]. In response to this, the Small Friends Books has produced several picturebooks to tell a story and incorporate scientific concepts on microbes [7]. Storybooks have been used to transmit engineering or science concepts at the Kindergarten, middle school, and high school levels, suggesting that their implementation at the university level could effectively transmit technical knowledge [26-28].

Education pedagogy encourages using multiple forms of delivery in the engineering classroom to engage different learning styles, specifically auditory, visual, kinesthetic, and the newly added reading/writing [29]. Activities that employ more than one learning style give students multiple ways to interact with the material, so students are more likely to absorb the content [30].

Storytelling using storybooks inherently incorporates multiple learning styles, and when coupled with appropriate activities, all learning styles can be accommodated. The use of storytelling can engage auditory learners if the story is read out loud. Visual learners can follow along with their own copy of the book. Kinesthetic learners are engaged if the story is complemented with a hands-on lab or experience. Students who learn through reading/writing are particularly benefitted through storytelling, especially if a writing

CEEA-ACEG21; Paper 085

University of Prince Edward Island; June 21-23, 2021-2 of 6- activity summarizing their learning follows the story's initial recitation.

\section{METHOD}

Storytelling was used as the vehicle to convey electronic concepts. A storybook was developed and illustrated to explain through a fictional narrative how to use a breadboard and make a simple circuit using a preprogrammed Arduino-nano, LEDs, resistors, wires, a 9V battery, and a breadboard. Appendix A contains sample pages from the storybook, showing the parallel lessons with technical information on the left page and the narrative on the right page. The story begins with 'Once upon a time, in a town far, far away, there was a village call "Breadboardia." On the corresponding page, there is a sketch of a breadboard and a simplified definition. The story explains how the town of Breadboardia learned to communicate and provide light at night, and the technical content on the corresponding page shows step-by-step instructions on how to connect a circuit to light up 3 LEDs. Resilience, determination, and creativity are explored throughout the book.

Students in one section $(n=28)$ read along with the storybook to learn about breadboards and basic electronic concepts. Students in a second section $(\mathrm{n}=43)$ used a traditional lecture to learn the same concepts that were addressed in the storybook, such as which holes on the breadboard are connected and component functionality (resistors, LEDs, Arduinos, etc). The lecture utilized visually engaging slides and was delivered using a dynamic presentation style. Efforts were made to ensure the content and duration of the lecture and storybook recitation were equivalent, so only the delivery method was different.

After the lecture or story was completed, participants were provided with an image of a simple circuit to replicate in order to light one LED. This was repeated with a second image and circuit in order to light 3 LEDs.

Finally, the participants completed a short assessment activity to demonstrate their understanding of breadboard concepts. Instructors were available to assist participants who requested help. The participants were timed to see how long it took to light up 1 LED and then to light up all 3 LEDs. The post-activity instrument included three qualitative items and two quantitative items on the operation of a breadboard, as well as the three items on participant data mentioned above.

The self-reported gender identity and experience level of participants in this purposive sample of students in a first-year engineering design course are listed in Table 1, as well as a summary of how much they enjoyed the activity.

The qualitative items were reviewed for specific elements, converted to individual quantitative items, and totaled as shown in Table 2. The duration and instrument data were entered into SPSS, cleaned, and analyzed using 
independent sample t-tests with a significance value of $\alpha<0.05$. All continuous items met assumptions of normality, independence of observation, and homogeneity of variances.

Table 1: Participant information.

\begin{tabular}{|c|c|c|c|}
\hline & $\mathbf{n}$ & $\begin{array}{l}\text { All } \\
(\%)\end{array}$ & $\begin{array}{r}\text { Novice } \\
\mathbf{n}\end{array}$ \\
\hline \multicolumn{4}{|l|}{ Delivery Method: } \\
\hline - $\quad$ Lecture & & $(39 \%)$ & 18 \\
\hline - $\quad$ Storybook & 43 & $(61 \%)$ & 30 \\
\hline \multicolumn{4}{|l|}{ Gender: My gender identity is: } \\
\hline - $\quad$ Female & 21 & $(30 \%)$ & 17 \\
\hline - Male & 50 & $(70 \%)$ & 31 \\
\hline - Non-binary & 0 & & 0 \\
\hline \multicolumn{4}{|c|}{ Engagement: Rate how much you enjoyed the activity } \\
\hline - Great! & 53 & $(75 \%)$ & 37 \\
\hline - This was fun & 17 & $(24 \%)$ & 11 \\
\hline - Same as any other day & 0 & & 0 \\
\hline - Not my favorite & & $(1 \%)$ & 0 \\
\hline - Never again & 0 & & 0 \\
\hline \multicolumn{4}{|c|}{ Experience: I used breadboards before today's class } \\
\hline - $\quad$ No & 48 & $(68 \%)$ & 48 \\
\hline - Yes, once & 4 & $(6 \%)$ & 0 \\
\hline - Yes, a few times & 8 & $(11 \%)$ & 0 \\
\hline - Yes, many & 11 & $(15 \%)$ & 0 \\
\hline Total & 71 & $100 \%$ & 48 \\
\hline
\end{tabular}

Data were reviewed to determine whether storytelling is as effective as traditional forms of teaching. It was expected that the participants in the storybook group would take longer to complete the activity because they would spend time flipping through the book, whereas the participants who received the lecture would be focused on replicating the schematic.

It was also expected that the participants with experience would complete the activity faster and have a higher competency than participants who did not report any experience with breadboards. For this reason and to isolate the effectiveness of storytelling for a new topic, the data from participants with self-reported experience with breadboards were used to validate the instrument and are not included in the reported results unless otherwise noted.

Participants with prior breadboard experience pose a threat to the validity of the study, and their responses will be used to provide construct validity, as it is expected that they will complete the activity faster and have a higher competency than participants who did not report any experience with breadboards. As participants are engineering students, they are predisposed to preferring analytical activities and therefore may report higher levels of enjoyment. Self-selection threats are minimized because this is a purposive sample.

In line with research ethics standards, the data were collected anonymously, and only one student elected to withdraw their data from the study, which indicates volunteer effects are minimized. The data of one additional student were lost to attrition as the participant did not have time to complete the activity. Students were seated 6 feet apart in line with COVID-19 social distancing standards, so communication among subjects was limited but not impossible. Content validity was reinforced by having an external reviewer for the instrument and storybook.

The only notable differences between the two participant groups were the delivery method and the number of participants. To reduce rater bias, data were randomized before the qualitative items were converted to quantitative scores.

Table 2: Qualitative items.

\begin{tabular}{|l|l|c|}
\hline On Instrument & Scoring Guide & $\begin{array}{c}\text { Max } \\
\text { Score }\end{array}$ \\
\hline $\begin{array}{l}\text { Item 1 What is a } \\
\text { breadboard? }\end{array}$ & $\begin{array}{l}\text { 1 point per reference: } \\
\text { - Form } \\
\text { - Fit } \\
\text { - Function } \\
\text { - Prototyping } \\
\text { - Electronics }\end{array}$ & 5 \\
\hline $\begin{array}{l}\text { Item 2 What is the red } \\
\text { rail generally used for? }\end{array}$ & $\begin{array}{l}\text { 1 point per reference: } \\
\text { - Power } \\
\text { - Positive }\end{array}$ & 2 \\
\hline $\begin{array}{l}\text { Item 3 An image of a } \\
\text { sample breadboard with }\end{array}$ & $\begin{array}{l}\text { a. 1 point for 'No' } \\
7 \text { labeled holes }\end{array}$ & 5 \\
$\begin{array}{l}\text { a. Are holes 1 \& 2 } \\
\text { connected? Y/N } \\
\text { b. Are holes 3 \& 7 } \\
\text { connected? Y/N } \\
\text { c. Which numbered } \\
\text { holes on the breadboard } \\
\text { are connected? }\end{array}$ & $\begin{array}{l}\text { b. 1 point for 'No' } \\
\text { c. 1 point for each: }\end{array}$ & \\
\hline - N \& 7 \\
\hline
\end{tabular}

\section{RESULTS}

The participants who were in the storytelling group completed the activities 12 minutes faster than participants who received a lecture, $t(1)=23.6, p<.001$. The participants in the storytelling group achieved a $6 \%$ higher mean score on the assessment than the participants who received a lecture, $p>.05$. Table 3 shows the descriptive statistics for the scores and time for each participant group.

The participants who used the storybook connected the first circuit (1 LED) 10 minutes faster than the participants who received a lecture, $t(1)=33.9, p<.001$. The difference in time to complete the second circuit (3 LEDs) was nonsignificant but indicated that the students who used the storybook completed the activity 1.6 minutes faster than the participants who received a lecture, $\mathrm{p}>.05$. 
The mean scores for items 1,2, and 3 on the assessment were $6 \%, 6 \%$, and $3 \%$ higher, respectively, for the participants who used the storybook than the control group. These differences were too small to be statistically significant, $\mathrm{p}>.05$.

Participants with any reported experience $(\mathrm{M}=14.2$ min, $\mathrm{SD}=10.0$ ) completed both activities 7 minutes faster $(\mathrm{t}(1)=2.0, \mathrm{p}=0.007)$ than participants with no prior experience $(M=21.2 \mathrm{~min}, \mathrm{SD}=9.9)$. Participants with any reported experience $(\mathrm{M}=7.95, \mathrm{SD}=2.3)$ had a $7.3 \%$ higher score $(p>0.05)$ on the assessment than participants with no prior experience $(\mathrm{M}=7.1, \mathrm{SD}=2.2)$. The higher scores and faster completion of activities for participants with experience instills confidence in the construct.

Table 3: Descriptive statistics.

\begin{tabular}{|c|c|c|c|}
\hline Delivery method & n & Mean (SD) & Min - Max \\
\hline \multicolumn{4}{|l|}{ Total Time (minutes) * } \\
\hline Lecture & 18 & $28.6(8.1)$ & $15-42$ \\
\hline Storybook & 30 & $16.8(8.1)$ & $7-42$ \\
\hline \multicolumn{4}{|c|}{ Time for 1 LED (minutes) $*$} \\
\hline Lecture & 18 & $21(6.3)$ & $12-32$ \\
\hline Storybook & 30 & $10.9(5.6)$ & $3-30$ \\
\hline \multicolumn{4}{|c|}{ Additional time for 3 LEDs (minutes) } \\
\hline Lecture & 18 & $7.6(5.2)$ & $3-18$ \\
\hline Storybook & 30 & $5.9(4.0)$ & $1-17$ \\
\hline \multicolumn{4}{|l|}{ Total Score (\#/12) } \\
\hline Lecture & 16 & $6.7(2.3)$ & $2-10$ \\
\hline Storybook & 21 & $7.4(2.0)$ & $3-11$ \\
\hline \multicolumn{4}{|c|}{ Item 1 Breadboard description (\# / 5 ) } \\
\hline Lecture & 18 & $2.7(1.1)$ & $1-5$ \\
\hline Storybook & 30 & $3.0(1.0)$ & $0-4$ \\
\hline \multicolumn{4}{|c|}{ Item 2 Power rail ( \# / 2 ) } \\
\hline Lecture & 16 & $1.3(0.6)$ & $0-2$ \\
\hline Storybook & 21 & $1.4(0.5)$ & $1-2$ \\
\hline \multicolumn{4}{|c|}{ Item 3 Connections ( \# / 5 ) } \\
\hline Lecture & 18 & $2.7(1.8)$ & $1-5$ \\
\hline Storybook & 30 & $2.8(1.4)$ & $1-5$ \\
\hline
\end{tabular}

$*$ significance $<.001$

\section{DISCUSSION}

These results indicate that using a storybook as the delivery method is as effective as a standard lecture and could increase the speed with which students complete introductory electronics activities. The different modality of having a story read to students could reinforce the importance of the activity simply due to its uniqueness.

One potential advantage of the storybook is that the lessons are immediately repeated as students use the stepby-step instructions alongside the story. This reinforces the relationship between the story and the concepts and has the potential to improve retention of the concepts. Though it would be interesting to measure the long-term effect, it is not possible for this group of participants as they are exposed to breadboards in multiple classes following this activity. The effect of the storybook cannot be isolated for any long-term effects.

It is possible that the faster time and better score were due to the step-by-step instructions provided in the storybook and not due to the story itself. However, this would have a larger effect on the time to complete the activity than it would on the assessment score. A follow-on study could examine this effect using three participant groups to isolate the effects: lecture and schematic, lecture and step-by-step manual, storybook with a step-by-step manual.

Item 2 had the lowest response rate. One explanation could be that the item was skipped because it was physically too close to the previous question in the instrument. This is supported by the fact that there was nothing to differentiate the times, scores, gender, experience level, or engagement for the participants that did not fill out item 2. If this item were particularly difficult, then it would be expected that participants who skipped the question did not score as well or took longer. The mean score for participants who completed the item was within the expected range for an average score (68\%), indicating a valid item. The placement of this item on the next instrument should be reconsidered.

An unexpected advantage of using the storybook during the delivery was the fewer number of requests for assistance. Though this was not recorded in this study, it would be interesting to measure how many interventions were required for each delivery method. With only 28 participants in the lecture group, much more assistance was needed than for the storybook group, which had 43 participants. This could account for the difference in mean times to complete the first activity than to complete the second activity, as participants who received the lecture may have spent time waiting for assistance for the first activity and adapted in the second activity.

Anecdotally, the most common mistake participants made was trying to connect the resistor and LED using rows occupied by other pins of the Arduino. This displays a lack of understanding of either how the rows in the breadboard are connected or the functionality of pins in an Arduino.

According to the literature, a storybook has the potential to increase engagement with the activity. However, this is difficult to measure because engineering students are predisposed to enjoy this type of hands-on activity. This predisposition is found in the data, as 70 out of 71 participants enjoyed the activity regardless of the delivery method, and only 1 participant did not enjoy the activity. Upon further examination, the participant who did not enjoy the activity was in the lecture group, had no prior experience, took longer than most students to complete the activities (34 $\mathrm{min}$ ), and had a slightly below-average score on the assessment (6/12). If there were more diverse 
engagement scores, the enjoyment could be compared to the performance as a potential influence.

\section{CONCLUSION}

The use of a storybook to convey technical content about breadboards for first-year engineering students was found to be as effective as using a lecture. It was shown that the storybook significantly reduced the time required for participants to complete the activity and produced a better mean score in an assessment of the activity. It would be warranted to repeat the study with storybooks containing different technical content for engineering students. The participant group could also be expanded to include non-technical audiences to see whether a storybook makes the content more accessible.

\section{Acknowledgements}

All procedures performed in this study involving human participants were in accordance with the ethical standards of UPEI REB per 6008912 Learning Electronics Through Storytelling. We are grateful for the support of UPEI to purchase materials and print the storybooks.

\section{References}

[1] Georgette Yakman, "STEAM Education: an overview of creating a model of integrative education," Middle Ground, pp. 15-16, 2012.

[2] Nicola Sochacka, Kelly Guyotte, and Joachim Walther, "Learning Together: A Collaborative Autoethnographic Exploration of STEAM (STEM + the Arts) Education," Journal of Engineering Education, vol. 105, no. 1, pp. 15-42, 2016. https://doi.org/10.1002/jee.20112

[3] Andrew D Watson and Gregory H Watson, "Transitioning STEM to STEAM: Reformation of Engineering Education," Journal for Quality \& Participation, pp. 1-4, 2013. Retrieved from www.asq.org/pub/jqp

[4] Aman Yadav, Dipendra Subedi, Mary A. Lundeberg, and Charles F. Bunting, "Problem-based Learning: Influence on Students' Learning in an Electrical Engineering Course," Journal of Engineering Education, vol. 100, no. 2, pp. 253280, 2011. https://doi.org/10.1002/j.21689830.2011.tb00013.x

[5] Savita K. Sugathan and Khairul Shafee Kalid, "An Exploratory Study of Storytelling Approach as an Instructional Tool from Educators' Perspective," In 2009 International Conference on Computer Technology and Development, 480-483.2009.

https://doi.org/10.1109/ICCTD.2009.122

[6] M. R. K. Krishna Rao, "Storytelling and Puzzles in a Software Engineering Course," In Proceedings of the 39th SIGCSE Technical Symposium on Computer Science Education.2006. https://doi.org/10.1145/1121341.1121472
[7] Gregory Crocetti and Briony Barr, "Teaching science concepts through story: Scientific literacy is more about the journey than the destination," Literacy Learning: the Middle Years, vol. 28, no. 3, pp. 44-52, 202AD.

[8] Deborah Fischer, "Storytelling as a Nursing Pedagogy," The Midwest Quarterly, vol. 60, no. 3, pp. 311, 2019.

[9] Carol Haigh and Pip Hardy, "Tell me a story - a conceptual exploration of storytelling in healthcare education," Nurse Education Today, vol. 31, no. 4, pp. 408-411, 2011. https://doi.org/10.1016/j.nedt.2010.08.001

[10] Christos H. Papadimitriou, "MythematiCS: In Praise of Storytelling in the Teaching of Computer Science and Math," SIGCSE Bull., vol. 35, no. 4, pp. 7-9, 2003. https://doi.org/10.1145/960492.960494

[11] Renato Bezerra Rodrigues, "Gamification in Engineering Education in Canada: A Systematic Review of the Literature," In Proceedings of the Canadian Engineering Education Association.2020. https://doi.org/10.24908/pceea.vi0.14142

[12] Cheryl A. Bodnar, Daniel Anastasio, Joshua A. Enszer, and Daniel D. Burkey, "Engineers at Play: Games as Teaching Tools for Undergraduate Engineering Students," Journal of Engineering Education, vol. 105, no. 1, pp. 147-200, 2016. https://doi.org/10.1002/jee.20106

[13] Azad M. Madni, Marcus Nance, Michael Richey, William Hubbard, and Leroy Hanneman, "Toward an Experiential Design Language: Augmenting Model-based Systems Engineering with Technical Storytelling in Virtual Worlds," In 2014 Conference on Systems Engineering Research, 848856.2014. https://doi.org/10.1016/j.procs.2014.03.101

[14] Andrew Roncin, "Rationale and Teaching Objectives for a Canadian Engineering Ethics Game," In Proceedings of the Canadian Engineering Education Association.2015. https://doi.org/10.24908/pceea.v0i0.5888

[15] Peter Ostafichuk, Carol Jaeger, and Jonathan Nakane, "Development of an Interactive Online Ethics Scenario Activity for Engineering Students," In Proceedings of the Canadian Engineering Education Association.2020. https://doi.org/10.24908/pceea.vi0.14144

[16] Hess Hodge, H. Hinton, and Michael Lightner, "Virtual Circuit Laboratory*," Journal of Engineering Education, vol. 90, no. 4, pp. 507-511, 2001. https://doi.org/10.1002/j.21689830.2001.tb00632.x

[17] J. Olin Campbell, John R. Bourne, Pieter J. Mosterman, and Arthur J. Brodersen, "The Effectiveness of Learning Simulations for Electronic Laboratories," Journal of Engineering Education, vol. 91, no. 1, pp. 81-87, 2002. https://doi.org/10.1002/j.2168-9830.2002.tb00675.x

[18] Benjamin Walsh and Michelle Spence, "Leveraging Escape Room Popularity to Provide First-Year Students with an Introduction to Engineering Information," In Proceedings of the Canadian Engineering Education Association.2018. https://doi.org/10.24908/pceea.v0i0.13054

[19] Albert E. Segall, "Science Fiction in the Engineering Classroom to Help Teach Basic Concepts and Promote the Profession," Journal of Engineering Education, vol. 91, no. 4, 
pp. 419-423, 2002. https://doi.org/10.1002/j.21689830.2002.tb00727.x

[20] Zafer I. Sakka and Imran A. Zualkernan, "Digital storytelling in higher education: a case study in a civil engineering laboratory," In Fifth IEEE International Conference on Advanced Learning Technologies, 365367.2005. https://doi.org/10.1109/ICALT.2005.124

[21] Tamara Ball, Linnea Beckett, Michael Isaacson, Linnea Beckett, and Michael Isaacson, "Formulating the problem: Digital storytelling and the development of engineering process skills," In 2015 IEEE Frontiers in Education Conference (FIE), 1-5.2015. https://doi.org/10.1109/FIE.2015.7344405

[22] Raffaele Fabio Ciriello, Alexander Richter, and Gerhard Schwabe, "When Prototyping Meets Storytelling: Practices and Malpractices in Innovating Software Firms," In 2017 IEEE/ACM 39th International Conference on Software Engineering: Software Engineering in Practice Track (ICSESEIP), 163-172.2017. https://doi.org/10.1109/ICSESEIP.2017.24

[23] Glen Bull, Denise A. Schmidt-Crawford, Michael C. McKenna, and Jim Cohoon, "Storymaking: Combining Making and Storytelling in a School Makerspace," Theory Into Practice, vol. 56, no. 4, pp. 271-281, 2017. https://doi.org/10.1080/00405841.2017.1348114

[24] Flavio Firmani, Sohad Kadhum, and Peter Wild, "Expanding Engineering Design with Mini Projects - Theory of Mechanisms a Pilot Course," In Proceedings of the Canadian Engineering Education Association.2015. https://doi.org/10.24908/pceea.v0i0.5873

[25] Patricia Caratozzolo, Álvaro Delgado, and Samira Hosseini, "Perspectives on the use of Serious-Storytelling for Creative Thinking Awareness in Engineering," Multimedia
Tools and Applications, vol. 76, no. 14, pp. 15707-15733, 2020. https://doi.org/10.1007/s11042-016-3865-5

[26] Zhihui Fang, "The Language Demands of Science Reading in Middle School," International Journal of Science Education, vol. 28, no. 5, pp. 491-520, 2006. https://doi.org/10.1080/09500690500339092

[27] Zenaida Aguirre-Muñoz and Michelle L. Pantoya, "Engineering Literacy and Engagement in Kindergarten Classrooms," Journal of Engineering Education, vol. 105, no. 4, pp. 630-654, 2016. https://doi.org/10.1002/jee.20151

[28] Amy N. Spiegel, Julia McQuillan, Peter Halpin, Camillia Matuk, and Judy Diamond, "Engaging Teenagers with Science Through Comics," Research in Science Education, vol. 43, no. 6, pp. 2309-2326, 2013. https://doi.org/10.1007/s11165-013-9358-x

[29] Norasmah Othman and Mohd Hasril Amiruddin, "Different Perspectives of Learning Styles from VARK Model," International Conference on Learner Diversity 2010, vol. 7 pp. 652-660, 2010. https://doi.org/10.1016/j.sbspro.2010.10.088

[30] M. Reza Emami, Michael C. F. Bazzocchi, and Houman Hakima, "Engineering design pedagogy: a performance analysis.," International Journal of Technology \& Design Education, vol. 30, no. 3, pp. 553-585, 2020.

\section{Appendix A: SAMPle StORYBoOK PAGE}

The storybook presents a fairy tale on the right-hand pages with the corresponding technical content on the lefthand pages. Figure 1 shows a sample page that introduces the power rails.

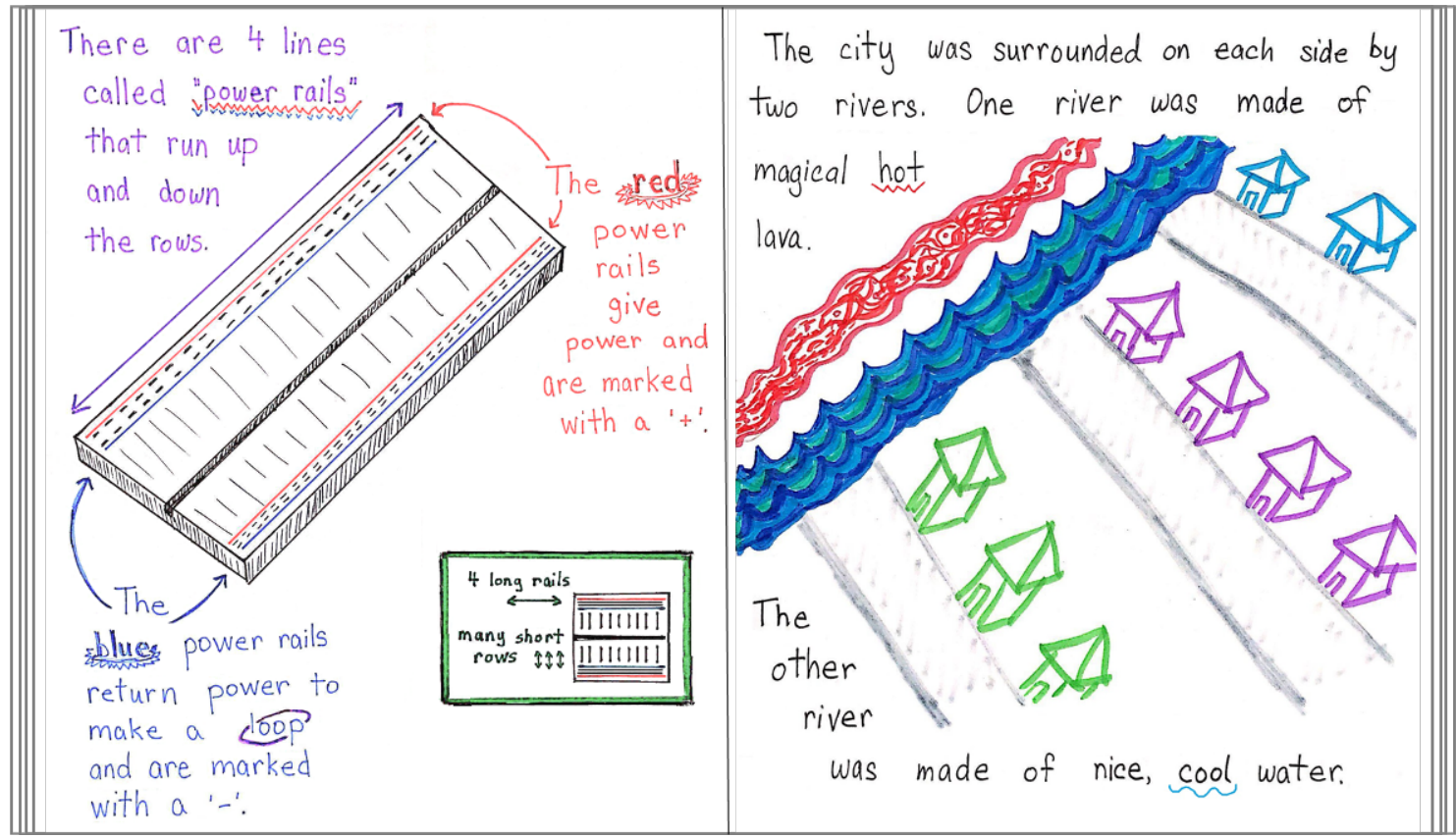

Fig. 1. Sample page.

CEEA-ACEG21; Paper 085

University of Prince Edward Island; June 21-23, 2021-6 of 6 - 